\section{$\underset{\substack{\text { hommes } \\ \text { \& migrations }}}{ }$}

\section{Hommes \& migrations}

Revue française de référence sur les dynamiques

migratoires

$1324 \mid 2019$

Religion et discrimination

\title{
Sema Kiliçkaya, La langue de personne
}

Ed. Emmanuelle Colas, Paris, 2018, 186 p., $15 €$

\section{Moustapha Harzoune}

\section{(2) OpenEdition}

1 Journals

\section{Édition électronique}

URL : https://journals.openedition.org/hommesmigrations/8721

DOI : 10.4000/hommesmigrations.8721

ISSN : 2262-3353

Éditeur

Musée national de l'histoire de l'immigration

Édition imprimée

Date de publication : 1 janvier 2019

Pagination : 225-226

ISBN : 978-2-919040-44-5

ISSN : 1142-852X

\section{Référence électronique}

Moustapha Harzoune, "Sema Kiliçkaya, La langue de personne », Hommes \& migrations [En ligne],

1324 | 2019, mis en ligne le 01 janvier 2019, consulté le 08 janvier 2022. URL : http://

journals.openedition.org/hommesmigrations/8721 ; DOI : https://doi.org/10.4000/

hommesmigrations.8721 


\section{La langue de personne}

Sema Kiliçkaya, Paris, éd. Emmanuelle Colas, 2018, 192 pages, 15 euros.

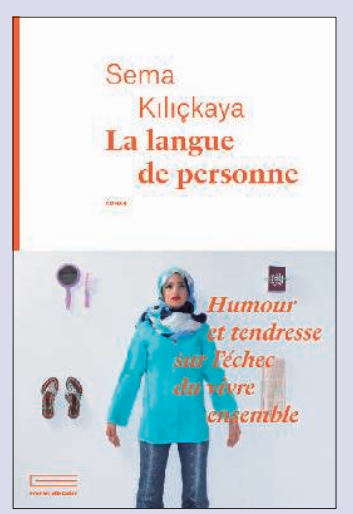

Il y a 25 ans, Fatma imprima une bifurcation dans sa vie, une bifurcation en forme de rupture. Couper le fil d'une narration engageait plus que son existence. En partant, elle rejetait les siens, un amour, un nom, une culture, un pays, une langue. Sauf à se perdre complètement, il y a des retrouvailles auxquelles on ne peut échapper. Fatma, devenue Victoria

par la magie de la «naturalisation», revient: son père est mourant et sa mère perd la raison, «le ventre de papa et la tête de maman». Retour dans l'appartement familial et cette HLM où les ombres du passé sont poussées vers le néant par les froids assauts du temps. La mémoire de Fatma "s'affranchit des interdits qu'elle s'était imposés». Elle tourne, telle une "lumière stroboscopique», réveillant de vieux souvenirs, éclairant le présent de couleur sépia.

La généreuse tunisienne du quatrième est partie, avec elle son couscous au "goût du paradis perdu». À sa place: une convertie de 13 ans, déguisée d'une burqa, et la majorité des femmes de la cité qui sont «fermées» (voilées). Elle est loin « la maison de grand-mère» qui sentait «le lait sucré», «l'enfance», «l'indulgence» à l'heure où l'on meurt à Charlie Hebdo. Envolée aussi la cadette. Elle s'est enfuie! Des trois sœurs, il ne reste que l'aînée, Elif, qui a enterré ses rêves sous des couches de silence, de frustration, de sacrifice. De ressentiment. Baba ne veille plus sur la famille, c'est désormais le Pacha qui commande. Lui qui numérote les bananes pour en vérifier la consommation et qui interdit à sa femme de se maquiller. Restent les enfants d'Elif. Décontractés, bruyants, à l'image de Demla qui se la joue «Muslim», cache son ignorance derrière les provocations d'une langue nébuleuse. Pour s'être redressés, "ces jeunes hypertrophiaient ce qu'on leur demandait d'atrophier. Ce faisant - et c'était là leur erreur -, ils mettaient en lumière la part la plus ténébreuse de la culture d'origine». La mère yoyote, cherche sa robe. «Quintessence [...] d'un rêve déchiqueté par la réalité», cette robe est celle qu'elle suspendait pour la protéger de la voracité des rats dans ces taudis réservés aux immigrés!

Un verre de Jurançon à la main, Fatma observe, comme extérieure. Elle se permet de corriger les fautes 
de français de sa nièce, de ramener sa science. Le ton est à l'humour, mais l'attitude est lourdingue. Elle consigne ses réflexions sur un carnet, note les mots des uns et des autres, les transformations et inventions des langues. Leur disparition aussi, «la migration de mes parents m'avait arrachée à ma langue natale». Les langues tournent en boucle, réseau, ramification, circulent, se font et se défont. Comme chez Amin Maalouf, ici "chaque langue vibre à l'écho d'une autre». Pourtant, les vertus du bilinguisme semblent s'arrêter à l'anglais et les cultures «révérées» sont rarement celles « de nos parents». Pire, au tribunal de l'Histoire, «le casier judiciaire» de certains pays reste étonnamment vierge, quand d'autres sont surchargés. Et, à l'heure où «les frères de mes parents tombent comme des mouches», qui dira la trahison de l'idéal européen? Sema Kiliçkaya, Boualem Sansal, Fawaz Hussain, Negar Djavadi...? Une langue de poètes, submergée sous le grand robinet de l'information continue.

Victoria note et morigène. Mais il faudra ôter le masque. Il faudra que Fatma entende le «Tu m'as laissée seule» de sa sœur, qu'elle réponde à la question de Baba, "Pourquoi es-tu partie?». Il faut reprendre le récit. Retrouver cette langue qui, débarrassée des illusions de l'origine ou de son déni, fasse de chacun des personnes et restaure ce qu'Arendt appelle dans son Journal de Pensée «l'équivocité chancelante du monde».

Sema Kiliçkaya ne donne pas dans la caricature télévisuelle et cinématographique de la Musulmane opprimée. Sesindignations vont au-delà. Elle montre les résistances, la complexité des êtres, des trajectoires. Les raisons d'espérer. Sa force de conviction est essentielle, réconfortante. La langue de personne a reçu le Prix France-Turquie 2018.

M. $\mathrm{H}$. 